\title{
INVERSION OF TOTAL SUSPENDED SEDIMENT IN TAIHU LAKE BASED ON MEASURED SPECTRAL DATA
}

\author{
XU, J. J. \\ Taizhou College, Nanjing Normal University, Taizhou 225300, China \\ (e-mail: $x \_j \_j 1981 @ 126 . c o m ;$ phone: +86-181-3665-8696) \\ (Received $7^{\text {th }}$ Jun 2019; accepted $10^{\text {th }}$ Oct 2019)
}

\begin{abstract}
The concentration of suspended sediments is an important indicator of the water quality of inland water bodies. Several single sensitive bands were employed to locate the bands in the mixed spectrum on water surface (WS-MS) that are sensitive to the TSS. However, this approach was proved wrong, for a high concentration of suspended sediment was derived from the WS-MS measured in the same water area under strong sunlight (i.e. high surface reflectivity). As a result, the single sensitive bands were replaced with the reflectivity ratio between the two bands most correlated with the TSS (the reflectivity ratio), such as to eliminate the impact of sunlight intensity. Correlation analysis shows that (R639 + R544)/(R639/R544) had closer correlation with the TSS than any other band combination. Based on the measured reflectivity ratio and concentration of suspended sediments, the TSS in the target water body was inverted separately by the least squares method and fuzzy regression. The results show that the inversion by fuzzy regression was not affected by measurement uncertainties or error, indicating that the fuzzy regression inverse model is more applicable than the least squares inverse model.
\end{abstract}

Keywords: sediment remobilization, reflectivity ratio, mixed spectrum on water surface (WS-MS), least squares method, fuzzy regression

\section{Introduction}

\section{Background and significance}

The SS concentration is a critical indicator for water environment evaluation. The SS (Suspended Sediment) refers to all particulate matters suspended in water, including organic detritus resulting from dead phytoplankton and inorganic suspension particles produced by resuspending terrestrial or lake sediments (Cai, 1998). In inland water, it is a more common phenomenon that there are the SSs, mainly seen in estuaries, coastal waters and shallow lakes with a high or low concentration affecting the sunlight transmission, the growth of underwater crops and the use of light by phytoplankton, and worse, the SSs may also change the aquatic ecological environment and restrict the primary productivity of the whole waters (Yang et al., 2002).

Foreign scholars have studied this area long ago. Traditional water quality monitoring in Lake Erie has been conducted using in situ and laboratory observations. The USEPA Great Lakes National Program Office (GLNPO) has conducted spring and July water quality sampling on Lake Erie since the early 1980s (Barbiero et al., 2018) and the NOAA Great Lakes Environmental Research Laboratory (GLERL) has been conducting weekly monitoring for over five years. Liu et al. (2019) also found in the study of hyperspectral remote sensing inversion that spectral reflectance ratio is more suitable for hyperspectral remote sensing inversion than single-band spectrum. The study of Binding et al. (2003) has shown that the optical parameters (backscatter coefficient and absorbance) in the water body are the most principal factors affecting the water reflectivity, affording a theory reference for quantitatively exploring suspended sediments. Suspended particles play an important role in coastal waters by controlling to a large extent the variability of the water inherent optical properties 
(IOPs). In this study, focused on the complex waters of the Southern North Sea, the relationships between the concentration, composition and size of suspended particles and their optical properties (light absorption, and attenuation in the visible and nearinfrared spectral regions) are investigated.

Some scholars in China have also attempted to explore the remote sensing inversion on suspended sediments since the 1980s. Shi et al. (2015) found that the spectral reflectance and total suspended solids had a strong correlation at $645 \mathrm{~nm}$ wavelength from the measured data of water body. Based on this, an empirical inversion model of total suspended solids with strong adaptability was developed and good results were achieved. Zhang et al. (2016) developed an analytical method to retrieve the total suspended solids by remote sensing in view of the complex situation of the turbidity and optical factors of Xinanjiang Reservoir, and achieved good results. Li et al. (2002) created the suspended sediment inversion model for the Yangtze River estuary at band ratio (R555 + R670)/(R555/R670). These studies have shown that the inversion of suspended sediment concentration using the remote sensing method is feasible. Cao et al. (2016) studied Nansi Lake and found that there was a relationship between the measured spectra and suspended matter concentration.

Owing to uneven distribution of TSSs in vertical space, it is difficult to measure TSS concentration with conventional water sample unable to timely reflect current water quality due to a manually realtime field inspection at a long cycle. In this study, given spectrum data as measured and the concentration at local sampling point, a TSS concentration inversion model can be built to monitor how the TSS changes in time and space in a timely manner.

\section{Materials and methods}

\section{Survey of study area}

Situated in the southern margin of the Yangtze River Delta, $30^{\circ} 55^{\prime} 40^{\prime \prime} \sim 31^{\circ} 32^{\prime} 58^{\prime \prime}$ latitude North and $19^{\circ} 52^{\prime} 32^{\prime \prime} \sim 120^{\circ} 36^{\prime} 10^{\prime \prime}$ East longitude, Taihu Lake is one of the five largest freshwater lakes in China. With the lakeshore line of $393.2 \mathrm{~km}$ in total length, the average water depth of $1.9 \mathrm{~m}$ and the maximum water depth of $2.6 \mathrm{~m}$, Taihu Lake has an average annual runoff of 7.5 billion $\mathrm{m}^{3}$, water storage capacity of 4.4 billion $\mathrm{m}^{3}$, and annual average water temperature of $17.1{ }^{\circ} \mathrm{C}$, that is, $4{ }^{\circ} \mathrm{C}$ in January, $25^{\circ} \mathrm{C}$ in July. The Taihu Lake covers a lake area of $2427.8 \mathrm{~km}^{2}$, the water area of $2338.1 \mathrm{~km}^{2}$. There are hilly mountains in the west and southwest sides, and plains and water net in the east.

As a shallow-water inland lake, Taihu Lake has suspended sediments mostly dominated by inorganic sediments and organic carbonized particles. Inorganic sediments derive from branch river system, and organic carbonized particles mainly come from some eutrophic remains of dead algae. Analyzing the curves of surface sediment fining and volume concentration as a function of time, we find that the suspended sediment particles are dominated by silt and clay.

Taihu Lake is open with strong wind, but moderate in the average depth. Therefore, the lakebed sediments are easily agitated, resulting in a higher concentration of suspended sediments in the water body. Over many years' water sample monitoring at the hydrological station, the concentration of suspended sediments in Taihu Lake varies in different times and spaces. In horizontal space, it is higher in the estuary area and the wind-agitating lake center, and low in the closed arm of lake (such as Meiliang Bay), 
but the minimum is in Dongtai Lake, mainly because there are lush hydrophytes, and less agitated suspended sediments.

\section{Data sample}

Data

The measured concentration used hereof is available from the lab, where the water sample is filtered and weighed after collecting at a sampling point preset (as shown in the figure), see Table 1 for specific data.

Here, water sample is available by the hierarchical collection method, namely, water is divided into three layers in depth: $0.2 \mathrm{D}, 0.5 \mathrm{D}, \mathrm{D}(\mathrm{D}$ is the water depth at the time of measurement), each takes $1 / 3$ of the water yield. Water samples collected from three layers are mixed.

In the lab, water sample is filtered and weighed by the following way: put $0.45 \mu \mathrm{m}$ filter membrane into an oven at $40{ }^{\circ} \mathrm{C}$, let it dry for $24 \mathrm{~h}$ at a constant temperature, and then remove the dried filter membrane from the oven and place it in a drying bottle to be stable, weigh it with a one ten-thousandth balance, then, number the filter membrane, and filter the water sample. The sediment available by filtration is placed in an oven at $40{ }^{\circ} \mathrm{C}$ and weighed with the above balance.

\section{Sample SS concentration analyzed in the lab}

The concentrations measured for SS samples available on November 13, 2017 (Fig. 1) and July 27, 2018 (Fig. 2) are shown in Tables 1 and 2.

Table 1. Concentration of SS samples (13/11/2017)

\begin{tabular}{c|c|c|c|c|c}
\hline Sample number & SS (mg/L) & Sample number & SS (mg/L) & Sample number & SS (mg/L) \\
\hline 1 & 31.40 & 9 & 23.35 & 17 & 30.56 \\
2 & 49.90 & 10 & 10.32 & 18 & 24.55 \\
3 & 39.33 & 11 & 54.08 & 19 & 36.72 \\
4 & 29.19 & 12 & 63.26 & 20 & 35.76 \\
5 & 28.34 & 13 & 33.61 & 21 & 29.43 \\
6 & 53.71 & 14 & 30.59 & 22 & 76.17 \\
7 & 69.21 & 15 & 48.74 & & \\
8 & 60.92 & 16 & 39.94 & & \\
\hline
\end{tabular}

Table 2. Concentration of SS samples (27/07/2018)

\begin{tabular}{c|c|c|c}
\hline Sample number & SS (mg/L) & Sample number & SS (mg/L) \\
\hline 1 & 54.15 & 9 & 66.05 \\
2 & 76.25 & 10 & 91.55 \\
3 & 81.35 & 11 & 72 \\
4 & 75.4 & 12 & 77.1 \\
5 & 81.35 & 13 & 72.85 \\
6 & 31.2 & 14 & 94.1 \\
7 & 97.5 & & \\
8 & 89 & & \\
\hline
\end{tabular}




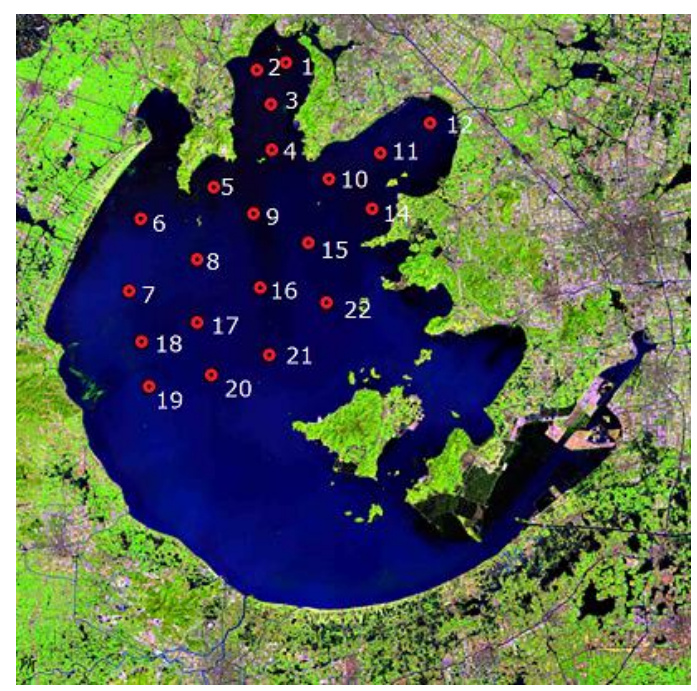

Figure 1. Distribution of samples (23/11/2017)

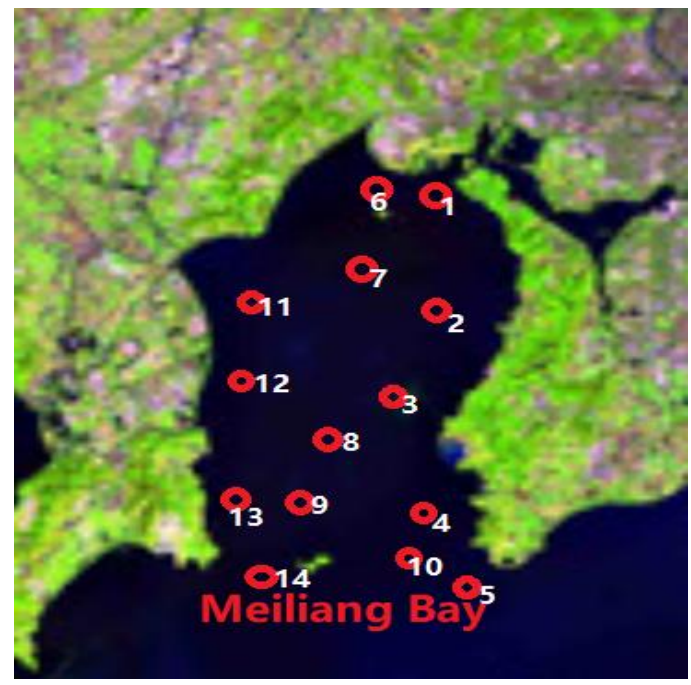

Figure 2. Distribution of samples (27/07/2018)

As seen from data measured in the lab, the concentration of suspended sediments in autumn is low, for example, the maximum in Table 1 is $76.17 \mathrm{mg} / \mathrm{L}$, the minimum is $9.44 \mathrm{mg} / \mathrm{L}$; the concentration of suspended sediments in July is high, for example, the maximum in Table 2 is $94.1 \mathrm{mg} / \mathrm{L}$, and the minimum is $66.05 \mathrm{mg} / \mathrm{L}$. However, due to the concentrated sampling points, there is a small gap between the maximum and the minimum.

\section{Hybrid spectrum signature measured on water surface}

On November 13, 2017, the hybrid spectrum on water surface was measured by a handheld ASD spectrometer of the United States at 22 points of the Meiliang Bay in North Taihu Lake (after removing the anomaly points, 16 points can be available), and treated by the ASD ViewSpec. During hyperspectral measurement, impacted by other external factors, the available SS spectrum has many tiny peaks, which makes it 
difficult to extract and analyze the spectral signature of suspended sediment. For this purpose, the characteristic wavelength corresponding to each reflection peak is analyzed. It is preferred to smooth spectral data (moving average, namely, five bands are chosen every time, and averaged as the center band value). Smoothing not only effectively eliminates the noise, but also retains useful information. The resulting spectrum curve is shown below.

In this area, 22 samples (14 out of them are available) are measured for remote sensing reflectance spectra using the same device on July 27, 2018, and the curve are shown in Figure 4.

As shown in Figures 3 and 4, two spectral curves available in November and in July differ a lot since chlorophyll spectrum features the reflectance peaks at around $550 \mathrm{~nm}$, around $620 \mathrm{~nm}$, around 700, and $820 \mathrm{~nm}$. Most strikingly, there is a reflectance peak appeared at around $700 \mathrm{~nm}$. Whether it appears or not is generally considered as the basis for determining whether there are lots of algae chlorophylls. These spectral signatures get blur when the algae concentration is low. Otherwise, water surface reflectivity sharply increases due to the strong reflectance of algae cells in the nearinfrared band if the algae bloom, as shown in Figure 4. In Figure 3, there is no similar signature (8\# sample is removed as anomaly point because there is phytoplankton on the lake). The too high concentration of chlorophyll has a effect on the overall spectral reflectance, so that the monodrome inversion will have a error.

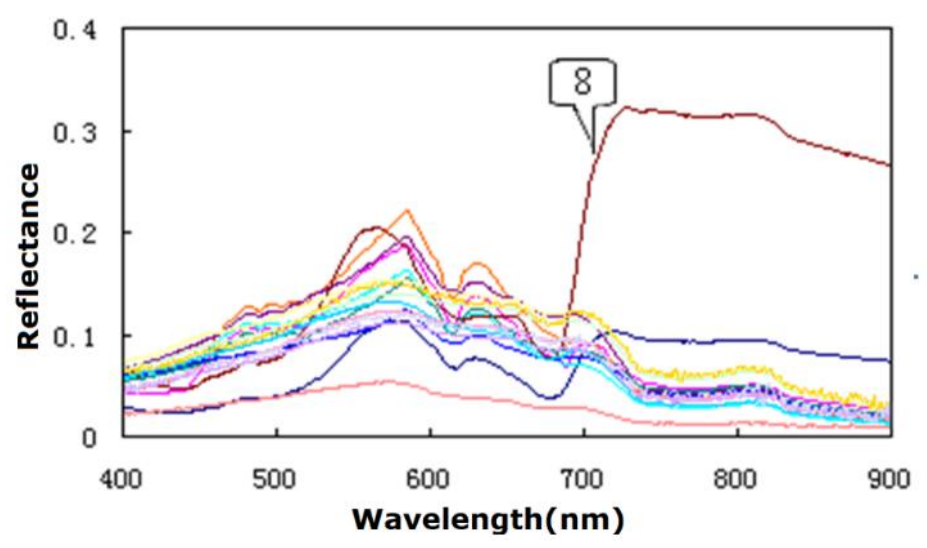

Figure 3. Curve of sample water surface reflectance spectrum in North Taihu lake (13-112017)

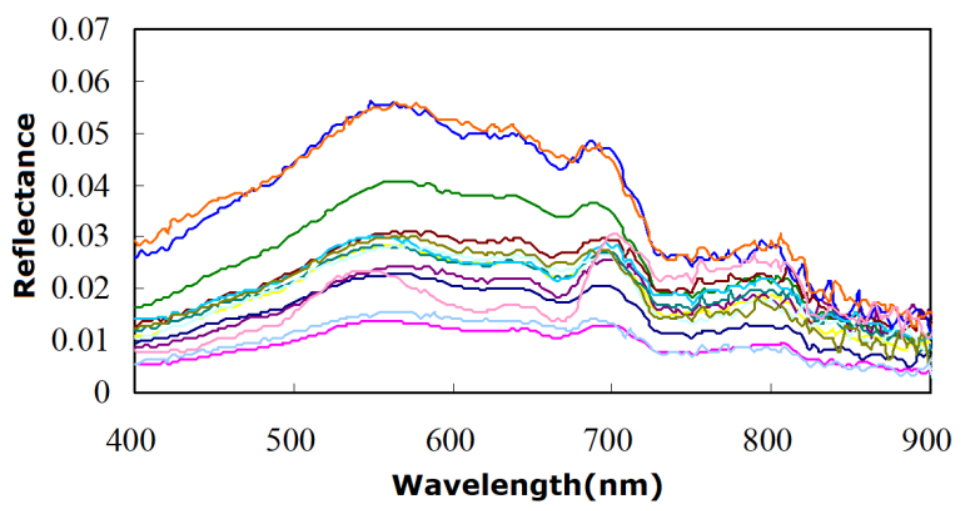

Figure 4. Curve of sample water surface reflectance spectrum in Meiliang Bay (29-07-2018) 


\section{SS-sensitive band analysis and inversion model construction}

\section{Establishment of linear regression model}

To extract the characteristic wavelength of the suspended sediment, the spectral curve, if used directly, will make it impossible to identify it. Introductory spectrum theory is used here. Based on the derivative spectrum theory, the second derivative of suspended sediment spectrum is preferentially obtained. Here, the wavelength in the visible light range is chosen for the following reasons: the "red shift phenomenon" will occur in the infrared band when the suspended sediment concentration is higher. As shown in Figure 5, the reflection peaks appear at $447 \mathrm{~nm}, 500 \mathrm{~nm}, 544 \mathrm{~nm}, 585 \mathrm{~nm}$, $593 \mathrm{~nm}, 623 \mathrm{~nm}, 639 \mathrm{~nm}$, and $695 \mathrm{~nm}$. The existing theory holds that the characteristic spectrum of suspended sediment is at $510-600 \mathrm{~nm}, 630-700 \mathrm{~nm}$, and derivative analysis concludes the characteristic wavelength that roughly coincides with the existing conclusion (Doxaran et al., 2002; Xue et al., 2012).

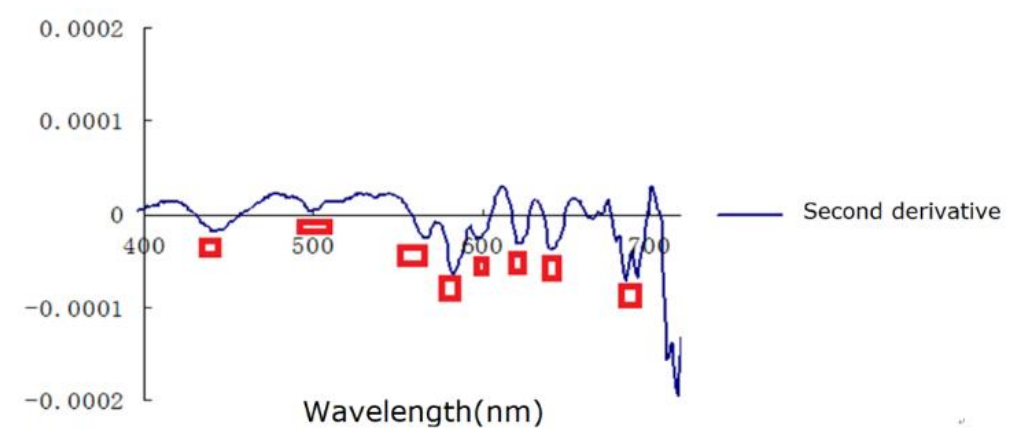

Figure 5. Second derivative and characteristic peak of suspended sediment spectrum

Since the second derivative of suspended sediment spectrum is very sensitive, some fine impure peaks are also erroneously assumed as characteristic peaks of the suspended sediment concentration. As a result, the correlation between the flux concentration and the measured spectral reflectivity is analyzed to further determine the characteristic peaks of suspended sediment spectrum. As shown in Figures 6 and 7, the characteristic peaks at $447 \mathrm{~nm}, 544 \mathrm{~nm}, 593 \mathrm{~nm}, 623 \mathrm{~nm}, 639 \mathrm{~nm}$ and $695 \mathrm{~nm}$ still exist, but are not highly correlated with the concentration of suspended sediments. In particular, it is almost irrelevant in the curve of the spectrum as a function of the concentration of sample (27-07-2017), mainly because the solar rays are too strong.

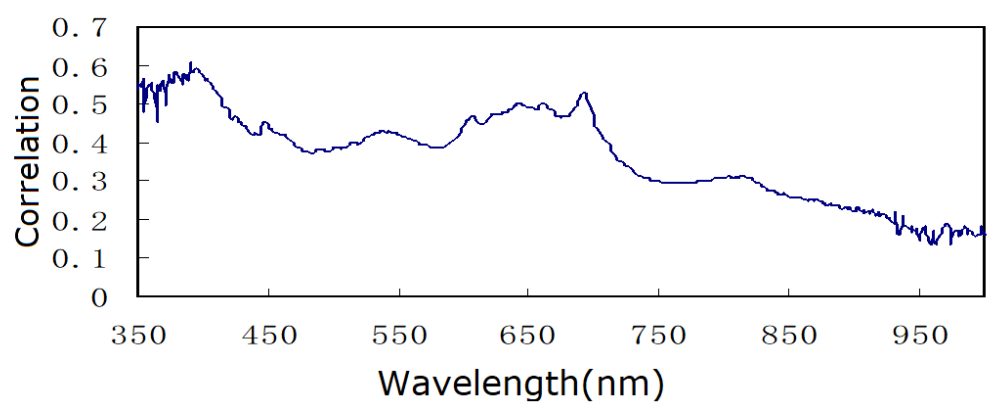

Figure 6. Correlation between spectrum reflectivity and suspended sediment concentration of sample (13-11-2017) 


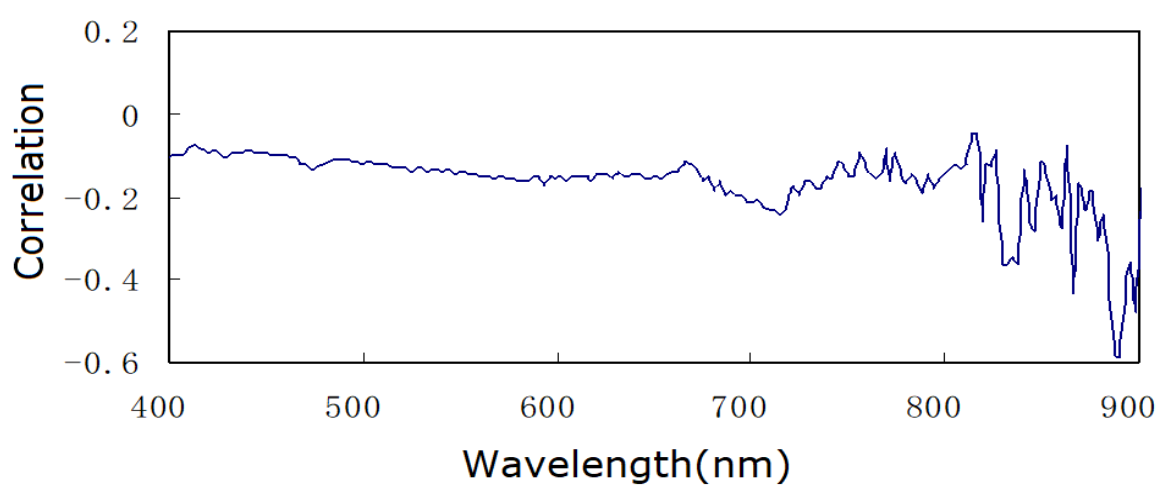

Figure 7. Correlation between remote sensing reflectivity and suspended sediment concentration of sample (13-11-2017)

To eliminate the interferences of solar ray intensity, ambient environment, water surface smoothness and other background factors, the characteristic spectrum ratio can be used (Pulliainen, 2011). The Chen et al. (1991) found that the natural logarithm of suspended sediment concentration is well correlated with water surface spectrum reflectivity, as shown in Figures 8 and 9.

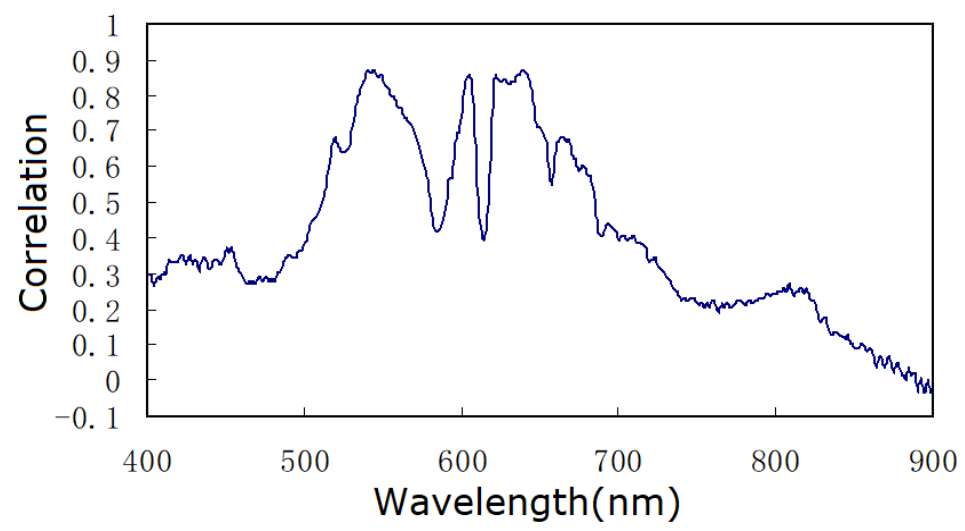

Figure 8. Correlation of the concentration (13-11-2017) logarithm with reflectivity ratio

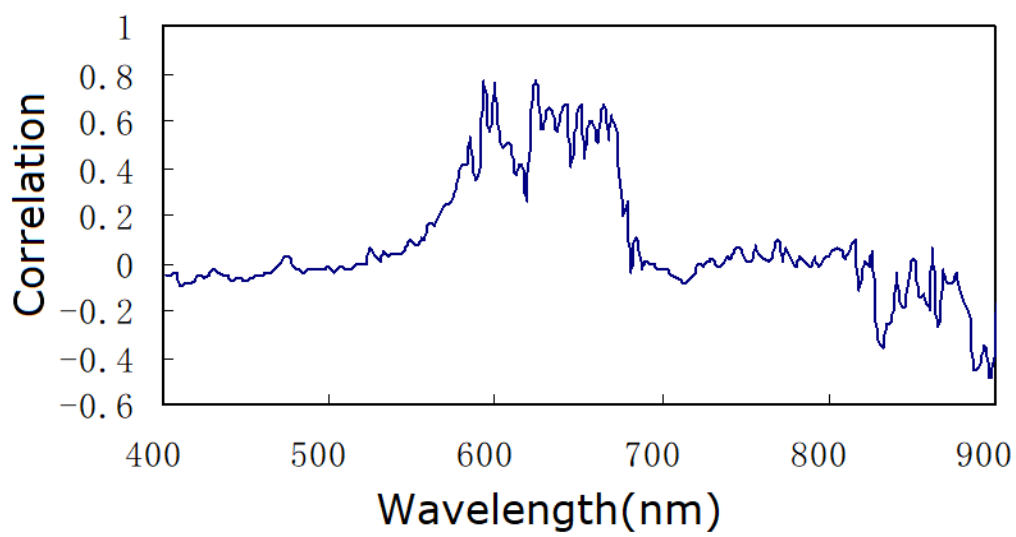

Figure 9. Correlation of the concentration (27-07-2018) logarithm with reflectivity ratio 
As shown in Figure 8, there is a high correlation between $530 \mathrm{~nm}$ and $680 \mathrm{~nm}$, and the first two values at which the correlation is higher are chosen to obtain the ratio. It is found that the maximum value in Figure 8 appears at R639 and R544 (consistent with the previous single-band characteristic peaks), i.e. R639/R544; in Figures 2-9, there is a high correlation between $580 \mathrm{~nm}$ and $680 \mathrm{~nm}$, and the first two values at which the correlation is higher are chosen to obtain the ratio. The maximum values appear at R623 and $\mathrm{R} 593 \mathrm{~nm}$ (consistent with the previous single-band characteristic peaks), i.e. R623/R593; the hybrid spectra measured on the surface of water bodies on 13-11-2017 and 27-07-2018 are respectively correspond to the $\operatorname{lnSS}$ (natural logarithm of the SS) to plot a scatter diagram and find the appropriate linear regression equation, as shown in Figure 10.

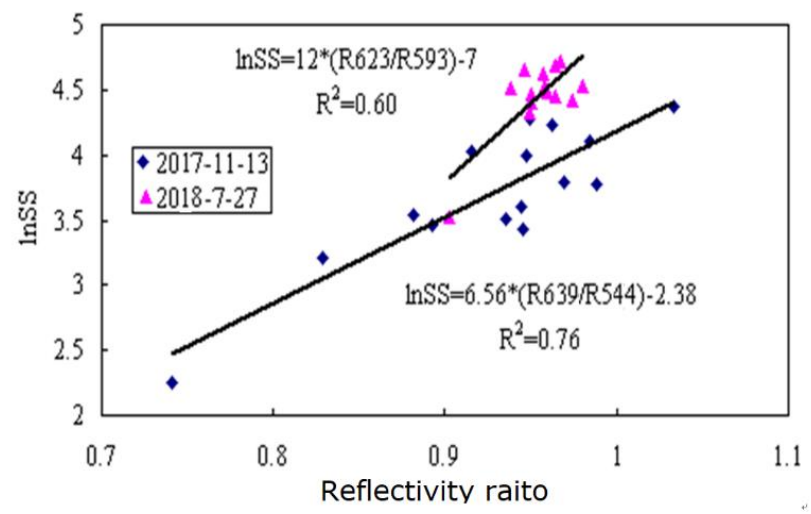

Figure 10. Relationship between reflectivity ratio and InSS

With the regression equation (see Fig. 1) fitted by the reflectivity ratio and $\operatorname{lnSS}$, the RMSEs (Root Mean Square Error) between the inverted SS concentration and the concentration of the sample in the lab are $10.79 \mathrm{mg} / \mathrm{L}(13-11-2017)$ and $14.99 \mathrm{mg} / \mathrm{L}$ (27-07-2018).

As seen from the RMSEs, the sample in November is significantly better than that in July. The main reason is that the solar intensity in July has an effect on the overall reflectance of the measured spectrum on the water surface. Next, in July, the phytoplanktons bloom in Taihu Lake due to the eutrophication of water bodies, blocking the projection of the SS spectrum onto the spectrometer. Therefore, the significance of the model in November $\left(R^{2}=0.76\right)$ is better than that in July $\left(\mathrm{R}^{2}=0.60\right)$.

Although the regression model in Figure 10 can be applied, there are still some errors due to the uncertainty of spectrometer and the laboratory SS quality error measured by $\mathrm{Hu}$ et al. (2004) and so on. However, this kind of error always changes around the model, so that the fuzzy regression method is used to establish the model hereof since it can eliminate the error caused by measurement and weighing. In fuzzy regression, spectral measurement and SS weighing errors are the inherent ambiguity of the system. The SS concentration inverted by the ratio of the measured spectra is not a value, but an interval (with the upper and lower bounds), i.e. it can take any value in this interval. Therefore, the fuzzy regression model focuses on the possibility rather than a specific value. 


\section{Establishment of fuzzy regression model}

The fuzzy regression model was first proposed by Tanaka and Watada (1998) in 1982, and the specific model is as follows:

$$
\tilde{Y}_{i}=\tilde{A}_{\mathrm{O}} x_{i \mathrm{O}}+\tilde{A}_{1} x_{i 1},(i=1,2,3, \ldots n)
$$

Let $x_{\tilde{i}}=\left(x_{i 0}, x_{i 1}\right)=\left(1, x_{i 1}\right)$, the fuzzy coefficients $\tilde{A_{0}}, \tilde{A_{1}}$ are usually the symmetric triangular fuzzy numbers, i.e. $\tilde{A}_{j}=\left(m_{j}, w_{j}\right), j=0,1$.

Its membership function is:

$$
\mu_{\tilde{A}_{j}}\left(n_{j}\right)= \begin{cases}1-\frac{\left|m_{j}-n_{j}\right|}{w_{j}} & { }^{\prime} m_{j}-w_{j} \leq n_{j} \leq m_{j}+w_{j} \\ 0 & \text {,other }\end{cases}
$$

where $m_{j}$ is the center value $\tilde{A}_{j} ; w_{j}$ is the span value. Then the membership function of $\tilde{Y}_{i}$ can be obtained using the extension principle, expressed as:

$$
\mu_{\tilde{Y}_{i}}\left(y_{i}\right)= \begin{cases} & 1-\frac{\left|y_{i}-x_{i} m\right|}{w^{T}\left|x_{i}\right|}, x_{i} \neq 0 \\ 1 & x_{i} \neq 0, y_{i} \neq 0, \forall i=1,2, \ldots . M \\ 0 & , x_{i}=0, y_{i}=0\end{cases}
$$

The last is to convert the fuzzy regression model into the following optimal model.

$$
\left\{\begin{array}{c}
\min \sum_{j=0}^{1}\left[w_{j} \sum_{i=1}^{M}\left|x_{i j}\right|\right] \\
1-\frac{\left|y_{i}-x_{i} m\right|}{w^{T}\left|x_{i}\right|} \geq h
\end{array}\right.
$$

where $0 \leq \square \leq 1, w \geq 0, w^{T}=\left(w_{0}, w_{1}\right), m^{T}=\left(m_{0}, m_{1}\right)$.

\section{Results}

The fuzzy level $h$ is arbitrarily set based on the number of samples, and the size of preset $h$ determines the model fitting degree. In general, when there are sufficient samples, $h$ should be set to as small as possible; the lower the fuzzy level, the smaller the span; when the number of samples is not enough, $h$ should be set to be as large as possible. In this case, the fitting degree builds up regardless of the rising fuzzy level. There are lesser samples collected in this project, so that the fuzzy level $h$ is set to 0.1 . With the natural logarithm of the SS concentration of laboratory measurement sample as the dependent variable, and R639 and R544 spectrum values as the independent variables, the fuzzy regression equation of the suspended sediment is available as below: 


$$
\ln \tilde{S}=(1.1678,0.9269)+(18.587,0) *(R 639+R 544) /(R 639 / R 544)
$$

\section{Discussion}

The built model should be tested for its fitness. In this study, the least square method is compared with the established fuzzy regression model. For the least square method as the statistical regression model, it is required to try to minimize the sum of the squares of the error between the inversion concentration and the observation value. A good fuzzy regression model should try to minimize the sum of absolute value of difference between the inversion concentration fuzz scope (the upper and lower bounds of the interval) and the observation value. The inversion results between the two are shown in Table 3.

Table 3. Least squares and fuzzy regression inversion of SS concentration

\begin{tabular}{|c|c|c|c|c|c|c|c|c|}
\hline $\begin{array}{l}\text { Sample } \\
\text { number }\end{array}$ & $\begin{array}{c}\text { Measurement } \\
\text { of suspended } \\
\text { solids } \\
\text { concentration } \\
\text { (mg/L) }\end{array}$ & $\begin{array}{c}\text { Prediction } \\
\text { results of } \\
\text { least } \\
\text { squares } \\
\text { method } \\
(\mathrm{mg} / \mathrm{L})\end{array}$ & $\begin{array}{c}\text { Prediction } \\
\text { results of fuzzy } \\
\text { regression } \\
\text { (lower bounds }) \\
(\mathrm{mg} / \mathrm{L})\end{array}$ & $\begin{array}{l}\text { Prediction } \\
\text { results of } \\
\text { fuzzy } \\
\text { regression } \\
\text { (central } \\
\text { value) } \\
(\mathrm{mg} / \mathrm{L})\end{array}$ & $\begin{array}{l}\text { Prediction } \\
\text { results of } \\
\text { fuzzy } \\
\text { regression } \\
\text { (upper } \\
\text { bounds) } \\
\text { (mg/L) }\end{array}$ & $\begin{array}{l}\text { Absolute } \\
\text { error of } \\
\text { least } \\
\text { square } \\
\text { prediction } \\
\text { (mg/L) }\end{array}$ & $\begin{array}{l}\text { Absolute error } \\
\text { of forecasting } \\
\text { lower boundary } \\
\text { value of fuzzy } \\
\text { regression } \\
(\mathrm{mg} / \mathrm{L})\end{array}$ & $\begin{array}{l}\text { Absolute } \\
\text { error of fuzzy } \\
\text { regression } \\
\text { center value } \\
\text { prediction } \\
(\mathrm{mg} / \mathrm{L})\end{array}$ \\
\hline 1 & 28 & 44 & 26 & 50 & 108 & -16 & 2 & -34 \\
\hline 2 & 29 & 47 & 27 & 54 & 117 & -18 & 2 & -38 \\
\hline 3 & 169 & 84 & 54 & 114 & 256 & 85 & 115 & 82 \\
\hline 4 & 169 & 128 & 90 & 198 & 447 & 41 & 79 & -43 \\
\hline 5 & 98 & 86 & 55 & 118 & 264 & 12 & 43 & -31 \\
\hline 6 & 169 & 212 & 168 & 381 & 869 & -43 & 1 & -318 \\
\hline 7 & 218 & 146 & 106 & 234 & 532 & 72 & 112 & -25 \\
\hline 8 & 104 & 142 & 102 & 227 & 515 & -38 & 2 & -185 \\
\hline 9 & 22 & 24 & 14 & 24 & 46 & -2 & 8 & -2 \\
\hline 10 & 18 & 33 & 18 & 34 & 70 & -15 & 0 & -23 \\
\hline 12 & 134 & 129 & 91 & 201 & 455 & 5 & 43 & -100 \\
\hline 13 & 106 & 128 & 89 & 198 & 446 & -22 & 17 & -137 \\
\hline 14 & 113 & 124 & 86 & 191 & 431 & -11 & 27 & -117 \\
\hline 15 & 25 & 24 & 14 & 23 & 44 & 1 & 11 & 3 \\
\hline 16 & 18 & 20 & 12 & 18 & 34 & -2 & 6 & 0 \\
\hline 17 & 78 & 36 & 20 & 38 & 78 & 42 & 58 & 61 \\
\hline 18 & 24 & 17 & 10 & 15 & 27 & 7 & 14 & 13 \\
\hline
\end{tabular}

As shown in Table 3: (1) Intuitively, it seems that the inversion of the least square regression model is better. In fact, that is not the case. The fuzzy regression reflects a concentration range, such as $1 \#$ sample, absolute error predicted by the least squares is 16. Although the absolute error of center value in the fuzzy regression model is high, the absolute error between the measured value and the lower bound is only 2 ; for $6 \#$ sample, for example, the absolute error of the center value in the fuzzy regression model reaches -318 , but the deviation from lower bound error is only 1. (2) Overall, the inversion effects of the least squares and the fuzzy regression are better. Fuzzy regression reflects a range of an interval, so is more flexible and greater in the information content. (3) There is a bit error in the high SS concentration area since original data for the model is mainly concentrated in the low concentration area, so that the high concentration has a poor fitness to the model that needs to be optimized later. 


\section{Conclusion}

Based on the measured spectra measured on the water surface and the SS concentration of the sample at different times, here draw the following conclusions:

(1) The model is built with spectrum data measured on the water surface and the SS concentration, the inversion effect is poor since single reflectivity value is greatly affected by the background factors. This paper uses the reflectivity ratio and the optimal bands R639/R544, R623/R593 and the SS concentration to build the inversion model for samples, for example, in July and November, respectively.

(2) Due to the uncertainty of spectrameter and the error of laboratory weighing on suspended sediment, the linear regression inversion model established has a poor significance. As a result, this paper attempts the fuzzy regression inversion model for suspended sediment concentration and compares it with the least squares method. It is found that the fuzzy regression model established herein gives not only the inversion concentration but also the interval in which the inverted concentration changes. The model features strong significance and fitness.

\section{Outlook}

The measured spectrum has great application potential in the monitoring of water quality in inland lakes. Because some theories and methods are still immature, its application is limited in water quality monitoring. In the study of the inversion model of total suspended solids in Taihu Lake, there are still some problems that need to be further solved.

(1) The particle size, mineral composition, surface roughness and color of the suspended solids cause significant differences in the spectral characteristics of the suspended solids. Therefore, in the estimation of suspended solids, the influence of different types of suspended solids should also be considered. Secondly, although the spectral characteristics of individual water quality parameters such as chlorophyll, suspended matter, and yellow matter are currently well understood by experimental means, the interaction between them is not well understood, so it is necessary to strengthen the analysis of the effects of chlorophyll and yellow matter on the concentration estimation of suspended solids in the future. It is only possible to establish a more accurate and effective model after separating the water quality parameters and clarifying the interaction between them.

(2) Since the sample data is still relatively small, the stability and representativeness of the model need further verification. In future works, the number of samples can be increased and the representativeness of the samples improved.

Acknowledgements. Research on network scheduling optimization model and method for monitoring camera in complex geographic scene (No. 18KJB170007).

\section{REFERENCES}

[1] Astoreca, R., Doxaran, D., Ruddick, K., Rousseau, V., Lancelot, C. (2012): Influence of suspended particle concentration, composition and size on the variability of inherent optical properties of the Southern North Sea. - Continental Shelf Research 1(7): 117-128. 
[2] Barbiero, R. P., Lesht, B. M., Hinchey, E. K. (2018): A brief history of the US EPA Great Lakes National Program Office's water quality survey. - Journal of Great Lakes Research 44(4): 539-546.

[3] Binding, C. E., Bowers, D. G., Mitchelson-Jacob, E. G. (2003): An algorithm for the retrieval of suspended sediment concentrations in the Irish Sea from SeaWiFS ocean color satellite imagery. - International Journal Remote Sensing 24(19): 3791-3860.

[4] Cao, Y., Yan, Y. T. (2016): Analysis of the relationship between hyperspectral measurements and suspended solids concentration and turbidity in Nansi Lake. - Water Resources and Power 36(1): 40-41.

[5] Doxaran, D., Froidefond, J. M., Lavender, S. (2002): Spectral signature of highly turbid waters: Application with SPOT data to quantify suspended particulate matter concentrations. - Remote Sensing of Environment 81: 149-161.

[6] Gordon, H. R., Wang, M. (1994): Retrieval of water leaving radiance and aerosol optical thicken Concentration of suspended solids over the oceans with SeaWiFS: a preliminary algorithm. - Applied Optics 33(3): 443-452.

[7] Hu, S. W., Xu, H., Yu, Z. Z. (2004): On the fuzzy uncertainty of remote sensing data. Mine Survey 4: 19-21.

[8] Li, S. H., Tang, J. W., Yun, C. X. (2002): Study on SeaWiFS remote sensing quantitative model of suspended sediment concentration in estuary. - Journal of Oceanography 24(2): 51-58.

[9] Liu, E. H., Zhou, G. S., Zhou, L. (2019): Fraction of absorbed photosynthetically active radiation over summer maize canopy estimated by hyperspectral remote sensing under different drought conditions. - Chinese Journal of Applied Ecology 6: 2021-2029.

[10] Pulliainen, J., Kallio, K., Eloheimo, K. (2011): A semi-operative approach to lake water quality retrieval Fuzzy regression remote sensing data. - The Science of the Total Environment 268: 79-93.

[11] Shi, K., Zhang, Y., Zhu, G. (2015): Long-term remote monitoring of total suspended matter concentration in Lake Taihu using $250 \mathrm{~m}$ MODIS-Aquadata. - Remote Sensing of Environment 164: 43-56.

[12] Tanaka, H., Watada, J. (1998): Possibilistic linear systems and their application to the linear regression model. - Fuzzy Sets and Systems 27(3): 275-289.

[13] Xue, Z. J., Jiang, C., Xu, L. G. (2012): The flocculation of fine-grained suspended sediment and its impact on spectral characteristics based on in situ measurement in the Changjiang Estuary, China. - Canadian Journal of Remote Sensing 49: 404-412.

[14] Yang, D. T., Chen, W. M., Zhang, Y. L. (2002): Distribution characteristics of suspended matter and spectra in Meiliang Bay of Taihu Lake. - Ecology Science 21(4): 289-293.

[15] Zhang, Y. B., Zhang, Y. L., Shi, K. (2016): A Landsat 8 OLI-Based, semi-analytical model for estimating the total suspended matter concentration in the slightly turbid Xin'anjiang reservoir (China). - IEEE 9(1): 398-413. 